\title{
Behaviour of uniaxially preloaded aluminium plates subjected to high-velocity impact
}

\author{
Shirley K. García-Castillo*, Sonia Sánchez-Sáez, Enrique Barbero \\ Department of Continuum Mechanics and Structural Analysis, University Carlos III of Madrid, Avda. de la Universidad 30, 28911 Leganés, Madrid, Spain ${ }^{1}$
}

\section{A R T I C L E I N F O}

\section{Article history:}

Received 1 April 2011

Received in revised form 26 May 2011

\section{Keywords:}

Uniaxial preload

Thin aluminium plate

Ballistic impact

Metals and alloys

Aerospace materials

\begin{abstract}
A B S T R A C T
The purpose of this paper is to evaluate the behaviour of structural thin plates made of 7075-T6 aluminium alloy under normal impact of spherical steel projectiles, when they are subjected to uniaxial in-plane tensile preload. Also, nonloaded plates were tested under high-velocity impact. The impact and residual velocity were measured in all tests. From the relationships between the impact and residual velocities, the ballistic limit was estimated by a least-squares method. No significant differences were found between the ballistic limits under the two loaded conditions. Above the ballistic limit in the preloaded plates, unstable cracks that can generate the catastrophic failure of the plate were observed. At similar velocities, this phenomenon was not observed in nonloaded plates.
\end{abstract}

\section{Introduction}

In the aeronautical industry, aluminium alloys are considered one of the most important engineering materials due to the need for low-weight aircraft structural elements. These elements can be subjected to accidental impact loads such as dropped tools, collisions, explosions, or fragment penetration.

This problem has been broadly studied in the literature, especially on thin plates. Usually, the authors estimate the ballistic limit and observe the failure modes. The ballistic limit can be defined as the velocity at which a particular projectile starts to penetrate the plate. The main failure modes of the thin plates when subjected to normal impact are ductile hole enlargement, petalling, plugging failure, dishing, membrane stretching and tensile tearing, and fragmentation. The failure modes depend on the projectile, material, thickness and impact velocity. Dishing could result at impact velocities slightly higher than the ballistic limit, and a transition from shear plugging to petalling and fragmentation could occur at higher-impact velocities as demonstrated by Dean et al. (2009).

Although the impact behaviour of aluminium plates, both thin and thick, and even in laminate form has been examined many studies, most analyse unloaded structures. However, it is rather

\footnotetext{
* Corresponding author. Tel.: +34 9162491 60; fax: +34 916248331.

E-mail address: sgcastil@ing.uc3m.es (S.K. García-Castillo).

1 http://www.uc3m.es/mma.
}

unlikely for structures not to be subjected to load over their service life.

A relatively small number of studies have analysed the behaviour of preloaded structures subjected to low-velocity impacts (Nettles et al., 1995; Whittingham et al., 2004; Herszberg and Weller, 2006; Heimbs et al., 2009; Minak et al., 2010). Some of these focus on plates undergoing a uniaxially in-plane load, tensile (Nettles et al., 1995) or compressive (Whittingham et al., 2004), subjected to a transversal impacts. It is broadly acknowledged that results from low-velocity tests cannot be extrapolated to high-velocity impact, and thus better data on the response to high-velocity impacts of preloaded structures are needed.

The studies on the behaviour of preloaded structures subjected to high-velocity impacts to date have considered only ceramic materials (Bao et al., 2002; Holmquist and Johnson, 2005) or composite materials (García-Castillo et al., 2006). In laminate composites plates, it has been observed that the presence of an in-plane preload altered the damage generated by the impact, and also slightly increased the ballistic limit (García-Castillo et al., 2006).

One of the few studies regarding the impact on preloaded metal structures was performed by Vedman et al. (2008), who experimentally analysed the effect of blast loading of preloaded aluminium plates.

In the present work, the influence of an in-plane uniaxial load on the ballistic behaviour of thin plates made of 7075-T6 aluminium alloy were analysed. Preloaded thin plates were experimentally tested under high velocity impact loads, and the residual velocity, ballistic limit, and failure modes were compared with those of nonloaded plates. 


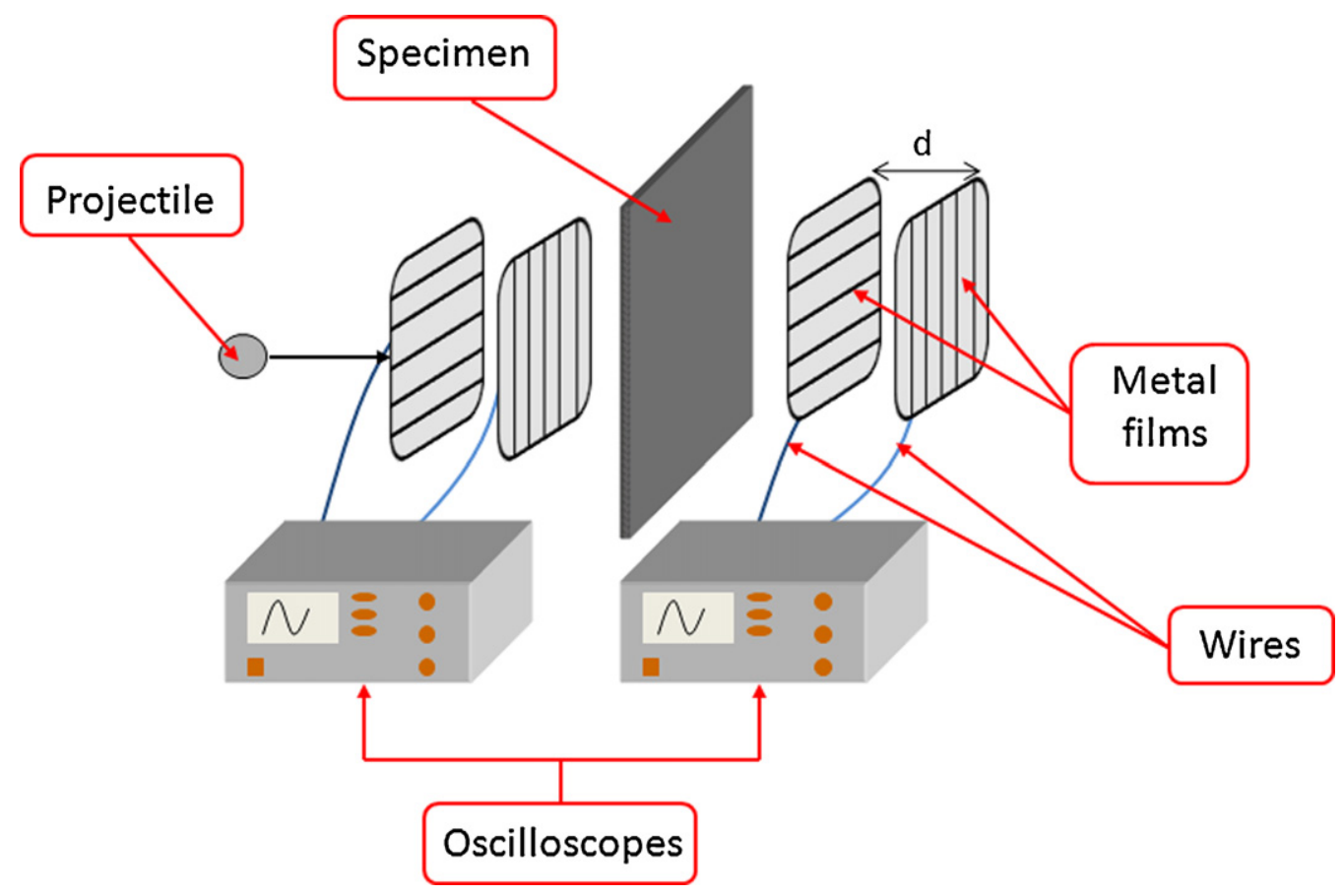

Fig. 1. Experimental device for the measurement of the impact and residual velocities.

\section{Experimental procedure}

In this work, tests were conducted using 12 specimens with a uniaxial in-plane tensile preload and 12 without preload. The specimens were made of 7075-T6 aluminium alloy of $1.5 \mathrm{~mm}$ thickness. The geometry of specimens used was of rectangular shape with the dimensions $140 \mathrm{~mm} \times 200 \mathrm{~mm}$.

To apply the preload, an experimental device was designed, which was coupled to a gas gun. This device had a system with a hydraulic cylinder, which applied a load of $51 \mathrm{kN}$. The load is applied on the upper and lower edges of the plate. These edges were clamped and the two other edges were unsupported.

All specimens were impacted by steel projectiles with a diameter of $12.5 \mathrm{~mm}$ and a mass of $8.33 \mathrm{~g}$, in the range of velocities from $100 \mathrm{~m} / \mathrm{s}$ up to $300 \mathrm{~m} / \mathrm{s}$ by one stage gas gun manufactured by SABRE BALLISTIC. During the impact tests, both the impact and residual velocity were measured by the device shown in Fig. 1. This system was made up two frames, which were placed at the front and at the back of the specimen. On each side of the frames, metal films were placed, with a wire connecting these to an oscilloscope. When the projectile perforated the metal films, the oscilloscope recorded the time that the projectile took to go through the frame thickness, and it was possible to calculate the impact and residual velocity.

\section{Results}

Fig. 2 shows the relationship between the impact and residual velocities for the preloaded and nonloaded plates. As reflected in these figures, the variation of the residual velocity of the projectile after perforation with the impact velocity is very similar for both plates.

The ballistic limit was calculated, using a least-squares method, by fitting the expression shown in the following equation, similar to those proposed in the model of Recht and Ipson (1963).

$v_{r}= \begin{cases}0, & 0 \leq v_{i} \leq v_{B L} \\ A \cdot\left(v_{i}^{p}-v_{B L}^{P}\right)^{1 / p}, & v_{i}>v_{B L}\end{cases}$

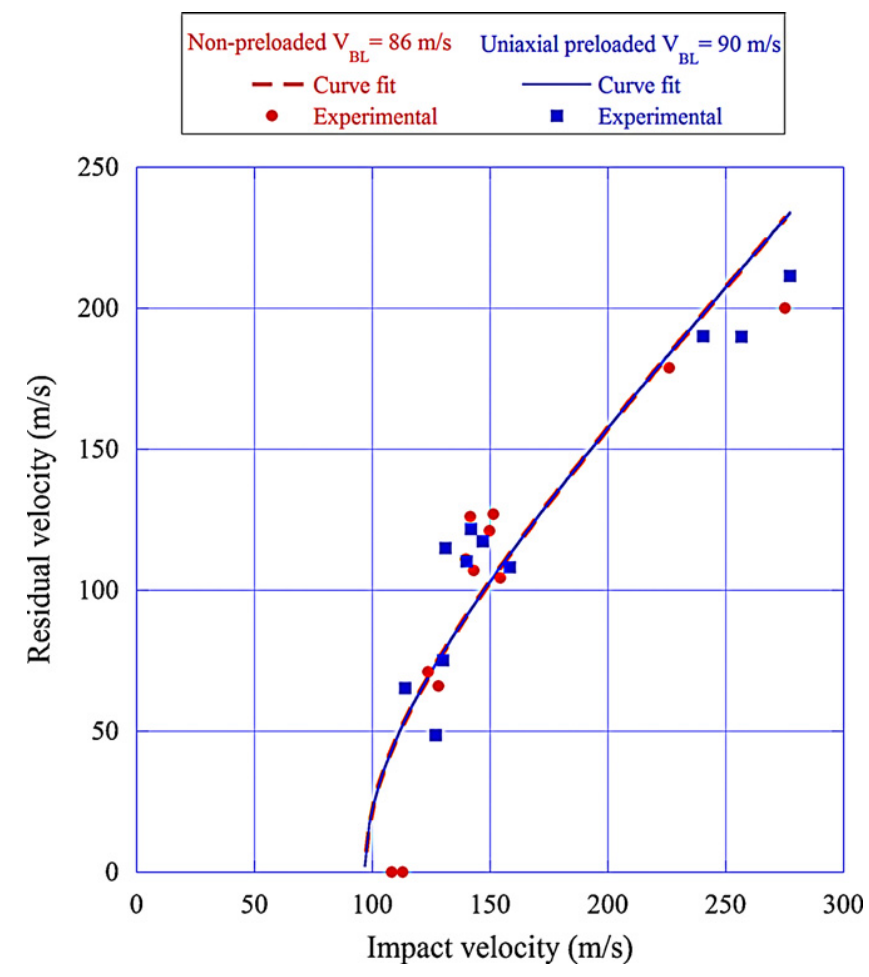

Fig. 2. Residual velocity vs. impact velocity in preloaded and non-preloaded plates.

where $v_{r}$ is the residual velocity, $v_{i}$ the impact velocity, $v_{B L}$ the ballistic limit, and $p$ and $A$ are fitting parameters.

The ballistic limit was $86 \mathrm{~m} / \mathrm{s}$ in the non-preloaded plates, and 90 in the preloaded plates. There was no significant influence of an in-plane tensile preload of $243 \mathrm{MPa}$, which was equal to $38 \%$ of the mechanical strength of the aluminium alloy, on the ballistic limit, because the difference between the two values was only $4.6 \%$. 

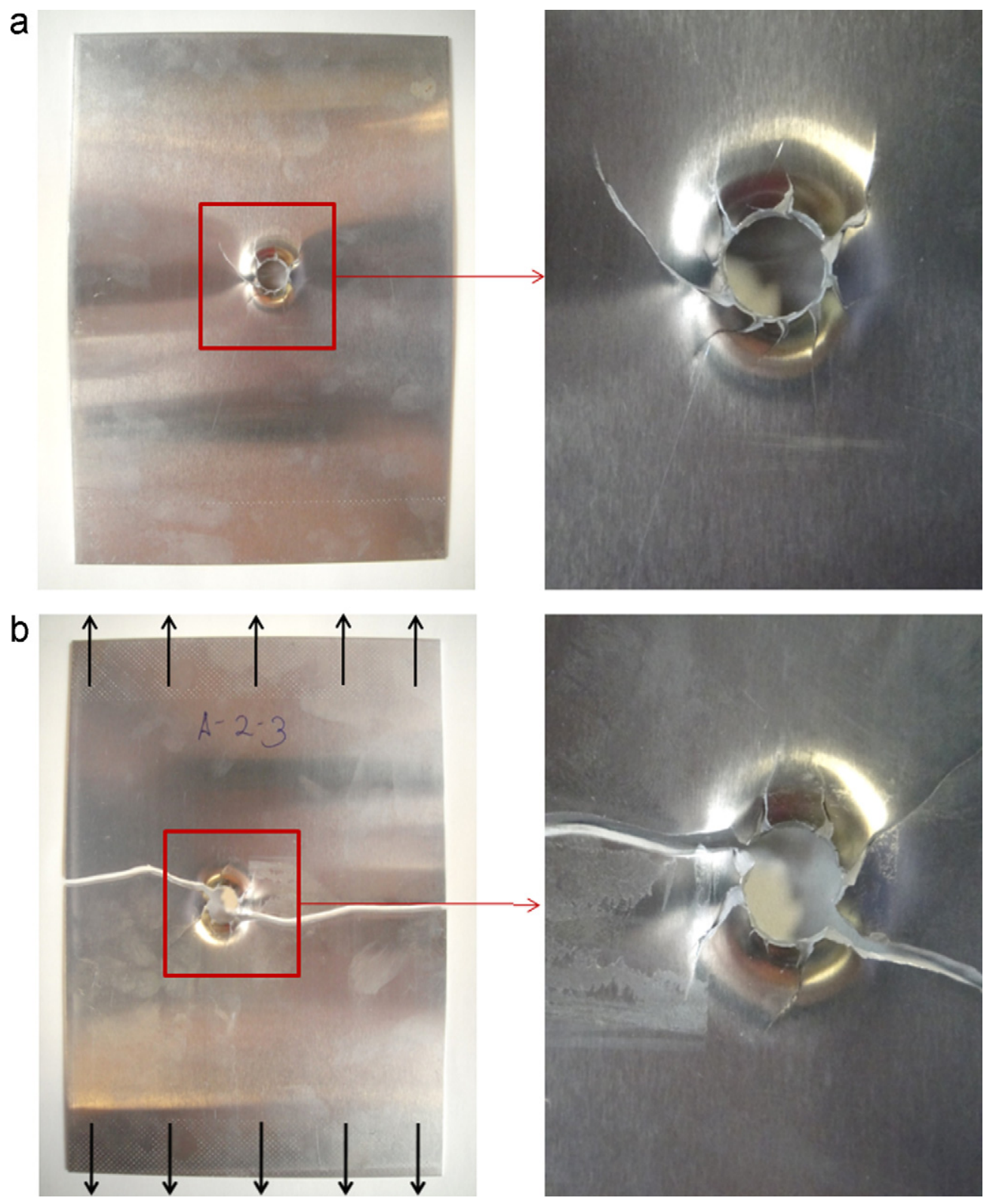

Fig. 3. Impacted thin aluminium plates at $127 \mathrm{~m} / \mathrm{s}$ : (a) nonloaded plates; (b) uniaxial in-plane preloaded plates.

In the non-preloaded plates the damage development during the perforation of the plate was located in a narrow area around the impact point. The damage evolution started from plastic deformation below the ballistic limit to shear plugging and petalling when the impact velocities increased. Around the hole formed by the perforation of the projectile, several cracks were visible (Fig. 3(a)).

The damage to the preloaded plates below the ballistic limit was also by plastic deformation. When the plate was perforated, the crack that formed around the hole grew perpendicular to the load direction, and resulted in a catastrophic failure of the plate (Fig. 3(b)). For all impact velocities above the ballistic limit, this phenomenon was observed. This failure suggests that, in this case, the cracks grew until failure mainly in mode I.

\section{Conclusions}

The influence of the in-plane tensile preload on the high velocity impact behaviour of aluminium alloy plates has been studied under high-velocity impact.
In preloaded as well as nonloaded plates, no significant differences were detected between the residual velocities measured and the ballistic limits estimated.

However, the failure mode differed when the impact velocity was above the ballistic limit. The preloaded plates underwent catastrophic failure, whereas this phenomenon did not occur in nonloaded plates. A preload of $38 \%$ of the mechanical strength is sufficient for the catastrophic failure of the loaded plates.

\section{Acknowledgement}

The authors are indebted to the Spanish Comisión Interministerial de Ciencia y Tecnología (Project MAT2001-0735) for the financial support of this work.

\section{References}

Bao, Y., Su, S., Yang, J., Fan, Q., 2002. Prestressed ceramics and improvement of impact resistance. Mater. Lett. 57, 518-524. 
Dean, J., Dunleavy, C.S., Brown, P.M., Clyne, T.W., 2009. Energy absorption during projectile perforation of thin steel plates and the kinetic energy of ejected fragments. Int. J. Impact Eng. 36, 1250-1258.

García-Castillo, S.K., Sanchez-Saez, S., Barbero, E., Navarro, C., 2006. Response of preloaded laminate composite plates subject to high velocity impact. J. Phys. IV 134, 1257-1263.

Heimbs, S., Heller, S., Middendorf, P., Hähnel, F., Weisse, J., 2009. Low velocity impact on CFRP plates with compressive preload: test and modelling. Int. J. Impact Eng. $36,1182-1193$

Herszberg, I., Weller, T., 2006. Impact damage resistance of buckled carbon/epoxy panels. Compos. Struct. 73, 130-137.

Holmquist, T.J., Johnson, G.R., 2005. Modeling prestressed ceramic and its effect on ballistic performance. Int. J. Impact Eng. 31, 113-127.
Minak, G., Abrate, S., Ghelli, D., Panciroli, R., Zucchelli, A., 2010. Low-velocity impact on carbon/epoxy tubes subjected to torque - experimental results, analytical models and FEM analysis. Compos. Struct. 92, 623-632.

Nettles, A., Daniel, V., Branscomb, C., 1995. The effects of tensile preloads on the impact response of carbon/epoxi laminates. In: 40th International Sampe Symposium , pp. 1019-1025.

Recht, R.F., Ipson, T.W., 1963. Ballistic perforation dynamics. J. Appl. Mech.-Trans. ASME. 30, 384-390.

Vedman, R.L., Ari-Gur, J., Clum, C., 2008. Response of pre-pressurized reinforced plates under blast loading. Int. J. Impact Eng. 35, 240-250.

Whittingham, B., Marshall, I.H., Mitrevski, T., Jones, R., 2004. The response of composite structures with pre-stress subject to low velocity impact damage. Compos. Struct. 66, 685-698. 